\title{
A Theoretical Assessment of the Impacts of Poor Risk Management in the Construction Industry - A Case of Ethiopia
}

\author{
Yisakor S. Ferede, Nokulunga X. Mashwama and Didibhuku W. Thwala \\ Dept of Construction Management and Quantity Surveying, University of Johannesburg, Johannesburg, \\ South Africa \\ SARChl in Sustainable Construction Management and Leadership in the Built Environment, Faculty of \\ Engineering and the Built Environment, University of Johannesburg, Johannesburg, South Africa
}

\begin{abstract}
The study examines previous literature on the impacts of poor risk management in construction industry, with specific aim of identifying the causes of poor implementation of risk management in construction projects. This is because the concept of risk management has attracted much attention in recent years and that researchers and research bodies, be it corporate or government that try to formulate remedies to poor risk management should begin with an understanding of the causes and impact of poor risk management. The totality of risk management in construction industries include the identification, measurement and prevention of all likelihoods of negative outcomes. The study is conducted with reference to existing theoretical literature, published and unpublished research. The study is mainly a literature review/survey on the cause and effects of poor risk management. One of the primary findings emanating from the study reveals that empirical studies have identified several important factors which causes poor risk management; such as project delays, project failure, reputational damages, and loss of profit, material scarcity, and inadequate project accountability amongst others. The study explores the causes and effects of poor risk management in construction projects and presents a robust background on the theories of poor risk management. This study will enable contractors, stakeholders and construction risk managers to achieve better result and quality projects.
\end{abstract}

(c) 2020 The Authors. Published by Budapest University of Technology and Economics \& Diamond Congress Ltd Peer-review under responsibility of the Scientific Committee of the Creative Construction Conference 2020.

Keywords: construction industry, construction projects, risk management

\section{Introduction}

Impacts of poor risk management in construction projects represents an important topic to study, some of the contracts or projects such as the construction of roads, hospitals, recreational facilities and schools are intended to improve the overall quality of life of the population residing in the jurisdiction of a particular municipality. However, with poor risk management to mitigate risks such as fraud, corruption and poor selection of competent service providers, most of the projects have either delayed or have completely failed [1]. In the period of progressive globalization, it's difficult to avoid risk, which has become an essential a part of daily life. Risk exist everyplace, in each aspect of our life. Effective risk management doesn't mean the removal of risk, which might apparently be the most cost-effective possibility [2].

\subsection{Overview of construction industry}

The Construction industry is multipart in nature since it calls for technology that is different, a fair color of the projects; a higher amount of organizational complexity, and various parties (client, permitting agency, Insurance, Bank, Supplier, consultant, contractor, and public). It's a significant role in the economic development of one society. Because it opens a chance for the massive employments to develop a 
marketplace for construction inputs providers as well as the services of its and the services delivered are feedback for various other sectors. As a result of the overwhelming investment of its, it is viewed as an economic uplifting of a nation. which is the reason why developing countries also invest in infrastructure development to improve their infrastructure status that's utilized to participate in the globalized world [3]. The construction industry plays a tremendous role in the economic system of developing countries. For instance, in several developing nations, significant construction pursuits account for approximately eighty percent of the entire capital assets, ten percent of the GDP of theirs, as well as over fifty percent of the money invested in fixed assets. Additionally, the Industry gives heavy employment opportunity and contribute considerable role to the economy of developing countries next to agriculture [4].

\subsection{Risk management in construction projects}

Construction projects contains numerous types of risks, including natural risks with climate systems (hurricane, typhoon, flood, etc.) along with geological methods (earthquake, volcanic eruption, geotechnical issues) along with human risks associated with a political, economic, financial, legal, well-being, managerial, complex, cultural and social dynamics [5]. Construction projects are extremely susceptible to risk due to higher spending, advanced interfaces, a range of stakeholders, integration of technologies, and materials, along with stringent timeframes. These problems are starting to be more and more complicated in the contemporary construction industry and related to other variables such as contractual, technical, and financial demands [6]. The construction is a risky industry, but plays a crucial part in turning the economic progress of developed and developing nations so management of risks in construction projects was recognized as an extremely crucial procedure to be able to accomplish the project goals in the terminology of the time, safety, quality, cost, and environmental sustainability. Identified risk management as a key tool in order to deal with construction risks and to overcome problems of task failure. Identified risk management as being a management tool which aims at finding energy sources of uncertainty and risk, determining the effect of theirs, and developing proper management responses. Moreover, risk management in the building project management context is a systematic and comprehensive method of determining, analyzing, and responding to risks to get the project goals. Risk management establishes the failure or success of construction projects [7].

Risk management is the summation of all systematic methods a company puts in place in order to reduce the likelihood of any threats and harms that may arise from uncertainties [8]. It involves the identification, measurement and response to project risks [9]. Various international and standardized organizations like IEC, PMI and PMBOK have agreed on risk identification, assessment, treatment and review of risks as the Three steps involved in risk management.

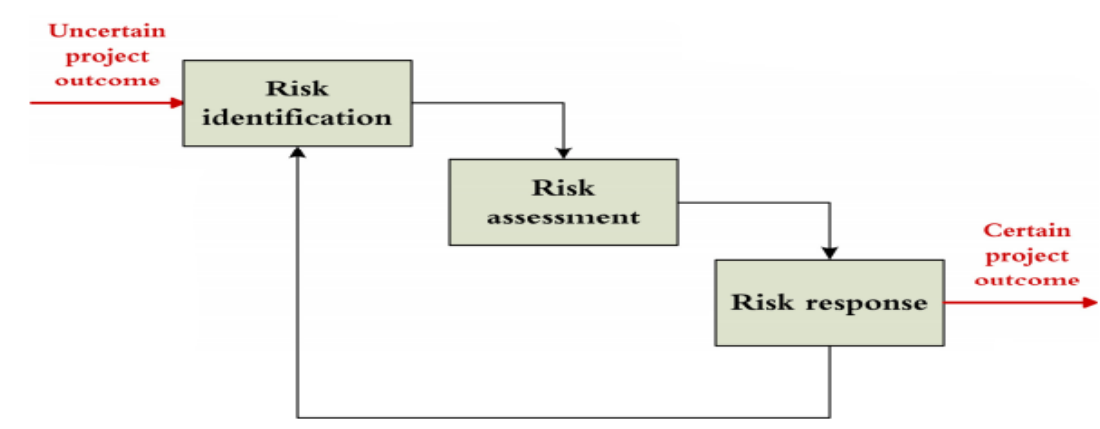

Fig. 1. Steps involved in risk management 


\section{Impacts of poor risk management in construction industry}

Risk management is a major aspect that can either influence a construction project positively or negatively depending on how it is done. A good risk management protocols when followed can lead to high capital value, better competitive advantage, maximum market profit margins, and good shareholder equity. In the same way, a poor risk management which involves the use wrong tools for risk management and control, inadequate utility of required management processes, poor quality of management and assessment can lead to big calamity in any construction project set-up [10]. Not regarding risk chances in a project can result into financial loss, bitter relationship between company/client and even a complete project failure. Hence, at the point of actions, when major elements are missing or lacking cases of project delays, reduced project quality and loss of company reputation are inevitable [11]. The various impacts of poor risk management are described below:

\subsection{Overgrowth of project cost}

Bad risk management results in the skyrocketing of running costs of a project work when the internal and external incongruences of the project cannot be well managed. Also, when construction bodies are not mindful and do not forecast the risks which can evolve from the execution of a contract, unreasonable and unplanned expenses like emergency and maintenance costs tend to creep in. This by-costs reduces how major plans are to be properly funded hence bringing down the overall quality of the stakeholders and managers goals [11]. Secondly, looking at the contractors and labour force side of view, most cost increments which occur on-site are as a result of various changes in client's demands. Therefore, improper understanding of the risks that can be incurred from specific clients can further encourage acute deviations from the already laid-out expenditure plans. Newly motivated interest in trending materials or labour from customers and clients causes higher pay rates which if not smartly overseen, can raise overall project costs wildly [6]. Poor risk management leads to overspending and thereby might cause the construction body to run into debt if not properly controlled. Risk management swallows a lot of expenses but the cost of dealing with the consequences of poor risk management is far beyond the former. It pushes the project team to look for more money which has not been budgeted for elsewhere in order to prevent the project from failing. Budget overruns therefore occurs when associated risks and their consequences are not budgeted for from the initiation of construction works [10].

\subsection{Project delays}

To a layman, delays happen when agreed date for completion or delivery of a project is past and the project is still not finished. Unanticipated and unpredicted risks which arises as a result of poor risk control strategies can reduce the speed of a work-plan because longer period is now needed to track, analyse, and correct this newly developed set of project risks. Project hold-ups or delays can also arise when risk management plans take longer periods and then push out other plans of the construction project. Therefore, risk management plans have to be responsive, efficient and most importantly timely and fast in order to overcome cases of project delays [12].

\subsection{Project failure}

Fundamentally, the worst-case scenario of poor risk management is project failures. It leads to invaluable output or production, waste of time, resources and thereby making the aims and objectives not achieved. When industrial risks are not foreseen, especially for new and innovative ideas in technological and construction circles, the project fails out-rightly. Each and every wrong risk management step taken by the administrative levels and stakeholders has a negative impact on how the products are delivered. Risks can destroy the profits and benefits of a project in an instance or gradually kills the profit of a contract till the construction bodies runs into debts or big losses and the project thereby fails and is closed [13].

\subsection{Loss of interest in the laid down management methods}

Generally, as a result of the human nature of the labour, when projects fails as a result of poor management decisions, the engineers and the low-level workforce can lose interest or focus in the methods with which they are instructed to follow. This further causes poorer output quality and low productivity because the 
labours are no more working according to the standard of best practice [12]. This loss of interests in the method or tools is also referred to as poor user adoption. It arises generally when the process of risk management is very bureaucratic and unnecessarily procedural; making the workers to design shortcuts for standard processes to keep the project on motion. From the managerial point of view, It also happens when the process is highly advanced, robust and rigid forcing the project supervisors and managers to adjust these risk management plans to create avenue for on-site changes [10].

\subsection{Reputational damage from customers}

Poor risk management often result into a significant reduction in the confidence of customers or clients for a company. These dis-satisfied customers in themselves pose another financial risk towards the company since one bad response or review from them can deter the image of the company. Therefore, serious attention must be given towards poor risk management and control strategies employed by an industry. Generally, clients do not like to be attached to establishments with high potential of risks in execution of projects. The consequences of poor risk handling do not only make clients to see the company badly, it also makes even sponsors and donors to move their businesses towards other competing industries. They are likely to bring down the reputation of the former companies they have worked with thereby making it hard for these companies to re-build their trusts in the long run [14].

\subsection{Loss of profit}

Financial risk management also includes system of double-signature requirements for checks, invoices, payables, stringent counting procedures. Inadequacy of protecting against embezzlement, theft, and fraud during a project execution because of porous administrative system can lead to potential profit loss. The quality of financial analytics and business risk assessment can determine how a project team make its profit or loss. Companies which have not employed proper risk mapping, identified the regularity of risks or evaluate risks based on significance cannot clearly notice the border line between profit and loss. Other channel of profit loss stems from expense related risks, cost increase, cost of reclaims and rework, employee-related risks etc. [15].

\subsection{Materials scarcity}

Scarcity of materials are common in construction projects. Lack of organizational plans in the procurement, transportation and records of construction materials can result into scarcity of material or impromptu finish of the materials. The choice of location to get the materials, poor estimation of the material quantity, inconsistent demands in the managerial cabinets, unforeseen government restrictions are all management factors that can lead to scarcity of construction materials. In more complex projects, when less quality logistics are put in place by the risk managers, the labour force tends to waste most of the materials thereby leading to the expiry of some materials, underutilization of some materials and complete consumption of other materials before another agreed time of a new order [16].

\subsection{Equipment damages}

The risks involved in the use of engineering tools and technological machines employed for building and road construction can be minimized if proper plan is channeled towards the training of personals. Unfortunately, most construction agencies make use of unskilled labors to achieve their goals; hence, this lack of good human risk cover or management scheme can result into life damages to the workers as these machines pose serious and injurious threats to the lives of the untrained workers. The cost of repairing damaged equipment also creates another minus in the overall project cost and it is as a result of poor risk management plans [17].

\subsection{Improper use of labour}

Talent acquisition and management are perhaps the most critical parts of the human resources department of any construction agency. Generally, improper resource planning and recruitment program may lead to overstaffing or understaffing and a mistake in the recruitment processes could lead to hiring the wrong people for your company, improper placement of workers for uncomplimentary jobs and underutilization of labour potentials [18]. 


\subsection{Inadequate project accountability}

Another impact of poor risk management is inadequate project accountability. An unclear view of the interdependencies between the projects, the benefits, and the criteria against which success will be judged can result into bad project accountability. It is imperative that a leader can work well with your team. When tasks or goals are not met to standard, there should be ramifications. Rank tasks by priority and assign them to the most proficient individual in the clearest way possible [14].

\subsection{Fear to explore new ideas}

Many managers sometimes think ideas don't solve critical problems especially when the relationship between the project team is not smooth. Hence when ideas from the workers or another low scaled labour takes too long to get to the decision board or gets too long to be acted upon, others become fearful to suggest new ideas. Also, risk management firms with slow decision cycles kills innovative ideas and thereby discourage others from voicing out their ideas [19].

\section{Lesson learnt}

This review work has helped to itemize various impacts of poor risk management through integrative research. It is hoped that this work will help researchers to tackle the various uncertainties in the field of construction projects. Poor management strategies can lead to bigger consequences or impacts. Other impacts of poor risk management include creation of negative working environment and underutilization of opportunities.

\section{Conclusion}

This work is a theoretical approach to increase the understanding of risk impact on construction projects. This will create a more effective risk management practice and help the identification, assessment and control of risks. Unplanned expenses, project delays, project failure, loss of profits, cost overgrowth are the major risk impacts identified while improper use of labour, materials scarcity, inadequate project accountability can be classified as the minor construction risk impacts identified in this work. A good risk management protocols when followed can lead to high capital value, better competitive advantage, maximum market profit margins, and good shareholder equity.

\section{References}

[1] Omwenga, L.K. \& Nasieku, T. (2016). Factors that influence risk management of public private partnerships in kenya's transport sector. International journal of social science and information technology, 2(VII):702-722.

[2] Szymański,P. (2017). Risk management in construction projectsPages 174-182. https://doi.org/10.1016/j.proeng.2017.11.036

[3] Belachew,A.S., Mengesha,W.J. \& Mohammed,M. (2017). Causes of Cost Overrun in Federal Road Projects of Ethiopia in Case of Southern DistrictScience Publishing Group. Pages $27-40$ https://doi.org/10.11648/j.ajce.20170501.15

[4] Yimam, A.H. (2011). Project management maturity in the construction industry of developing countries (the case of ethiopian contractors), https://doi.org/10.1007/s42524-019-0070-z.

[5] Ling, F.Y.Y. and Hoi, L., 2006. Risks faced by Singapore firms when undertaking construction projects in India. International journal of project management, 24(3), pp.261-270. https://doi.org/10.1016/j.jproman.2005.11.003

[6] Perez, David, Gray, Jason, Skitmore, Martin (2016) Perceptions of risk allocation methods, equitable risk distribution: A study of medium to large Southeast Queensland commercial construction projects. International Journal of Construction Management, 17 (2). https://doi.org/10.1080/156223599.2016.1233097

[7] Akinbile, B.F., Ofuyatano, M., Oni, O.Z. \& Agboola, O.D. (2018). Risk management and its influence on construction project in nigeria. Annals of the faculty of engineering hunedoara, 16(3):169-174. www.fih.upt.ro

[8] Project Management Institute (PMI) (2013) Project Management Body ofKnowledge (PMBOK), 5th ed. USA: Project Management Institute, Inc.

[9] Chapman, C. and Ward, S., 2011. How to manage project opportunity and risk. Jonh Wiley and Sons Ltd.

[10] Dosumu, O., \& Aigbavbo, C. (2018). Perceived impacts and solution to poor project management on abandoned construction projects. Creative Construction Conference 2018 - Proceedings.https://doi.org/10.3311/ccc2018-082

[11] Ratsiepe,K.B. \& Yazdanifard,R. (Aug 2011). Conference proceedings of the Xth conference held in Y. IEEE. https://doi.org/10.1109/ICMSS.2011.5999104

[12] Krausmann, E., Girgin, S., \& Necci, A. (2019). Natural hazard impacts on industry and critical infrastructure: Natech risk drivers and risk management performance indicators. International Journal of Disaster Risk Reduction, 101163. https://doi.org/10.1016/j.ijdrr.2019.101163

[13] Halou, M. I. K., Samin, R., \& Ahmad, M. (2019). Impacts of change management on risk and cost management of a construction projects. Journal of Project Management, 157-164 https://doi.org/10.5267/j.jpm.2019.1.005

[14] Adeleke, A. Q., Bahaudin, A. Y., \& Kamaruddeen, A. M. (2017). Organizational Internal Factors and Construction Risk Management among Nigerian Construction Companies. Global Business Review, 19(4), 921-938.https://doi.org/ 10.1177/0972150916677460 
Proceedings of the Creative Construction e-Conference (2020) 016

Available online at e-2020.creative-construction-conference.com/proceedings/

[15] Rutkauskas, A.V. and Stasytytè, V., 2010. Effectiveness, reliability and subject risk-shaping drivers for the set of possibilities and utility function when investment decision is made under uncertainty https://doi.org/10.3846/bm.2010.025

[16] Forssbæck, J., Oxelheim, L., \& MacKay, P. (2014). Transparency of Corporate Risk Management and Performance. The Oxford Handbook of Economic and Institutional Transparency. https://doi.org/10.1093/oxfordhb/9780199917693.013.0024

[17] Ozolins, P., 2014. Sustainability \& Scarcity: A Handbook for Green Design and Construction in Developing Countries. Routledge. https://doi.org/10.4324/9781315760940

[18] Cartwright, D. (Sept 5, 2017). Top ten challenges facing small construction companies. Buildsoft. Retrieved from https://www.buildsoft.com.au/blog/top-10-challenges-facing-small-construction-companies.

[19] Palermo, T. (2014). Accountability and Expertise in Public Sector Risk Management: A Case Study. Financial Accountability \& Management, 30(3), 322-341. https://doi.org/10.1111/faam.1203. 